\title{
Os espaços externos como possibilidade de múltiplas experiências na Educação Infantil
}

Neste texto abordamos a relação das crianças e profissionais com os espaços externos das instituições de Educação Infantil, a partir de uma experiência vivenciada no Estágio em Docência em Educação Infantil no Curso de Pedagogia da Universidade Federal de Paraná. O estágio foi realizado em um Centro Municipal de Educação Infantil de Curitiba, durante o ano letivo de 2013 , com encontros semanais, sendo as observações de campo realizadas predominantemente no período vespertino, com dois grupos de crianças organizados por idade de acordo com a instituição. A base teórica está constituída por uma breve análise dos documentos mandatários da educação infantil, as concepções de espaços e as interações, estabelecendo uma relação com as práticas vivenciadas e com a teoria histórico-cultural. Nosso foco de análise se constituiu nos espaços e nas suas organizações, bem como possibilidades de experiências das crianças a partir das relações sociais e com a natureza, que se estabelecem no espaço externo. Nesse sentido, abordamos a importância da consideração dos espaços externos nos planejamentos e práticas pedagógicas, ampliando o contato das crianças com os elementos da natureza, assim como as situações de brincadeira e movimento.

Palavras chave: Educação Infantil; Espaços Externos; Estágio em Docência.

\section{The outer spaces as possibility of Multiple Experien- ces in Early Childhood Education}

In this text, we glance at the relationship between children and professionals, within the outer spaces of educational institutions, while interning as a teacher through Parana's Federal University Pedagogy Course. The internship was held at a Curitiba's Municipal Kindergarten during the 2013 school year. It consisted of weekly meetings with field observations, made mostly during the evenings, with two groups of children organized by age, in agreement with the institution. The theoretical basis is composed by a brief analysis of children's education documents and the conceptions of spaces and interactions - providing a relationship between experienced practices and the cultural-historic perspective. Our analysis focused on the spaces and their organizations. Also, on the possibilities of children's experiences concerning social relations and contact with nature, established on the outer spaces. In doing so, we approach the importance of outer spaces on pedagogical planning and activities, increasing the children's contact with natural elements, in the same way as movement and play situations.

Keywords: Early Childhood Education; Outer Spaces; Teaching Internship.

\footnotetext{
I Acadêmica do Curso de Pedagogia, do Setor de Educação da Universidade Federal do Paraná, professora na Educação Infantil. E-mail: jana_amonteiro@yahoo.com

2 Acadêmica do Curso de Pedagogia, do Setor de Educação da Universidade Federal do Paraná, professora nos Anos Iniciais do Ensino Fundamental. E-mail: jessikaklaus@hotmail.com
} 


\section{Introdução'}

O atendimento em creches e pré-escolas como direito social das crianças se afirma na Constituição Federal (BRASIL,1988) com o reconhecimento da Educação Infantil como dever do Estado. A Lei de Diretrizes e Bases no 9394 (BRASIL, 1996) define a educação infantil como primeira etapa da educação básica, tendo por finalidade o desenvolvimento integral da criança até cinco anos de idade, o que nos leva a entender a relevância dos Centros de Educação Infantil como espaços fundamentais para a efetivação dos direitos das crianças.

Ao localizar a educação infantil como um direito das crianças, identifica-se um conjunto de aspectos que precisam ser discutidos no sentido de assegurar uma educação infantil de qualidade. Nesse sentido, elegemos o espaço externo das instituições de educação infantil como foco de análise, o compreendendo como um lugar que oportuniza a interação entre as crianças e seus pares, destas com os adultos e com o meio. O espaço externo pode proporcionar muitas experiências envolvendo a brincadeira, a expressão por meio do corpo, das relações com a natureza, da imaginação e da criação, tornando-se um lugar de expressão da infância e um elemento educativo.

A partir desta concepção inicial, o presente artigo propõe-se a discutir e analisar o espaço externo das instituições de educação infantil a partir de uma perspectiva histórico-cultural, estabelecendo relação com as observações de campo realizadas em um Centro Municipal de Educação Infantil vinculado à rede de ensino de Curitiba, mediante o Estágio em Docência em Educação Infantill do curso de Pedagogia da Universidade Federal do Paraná; o qual se realizou durante o ano letivo de 2013, com encontros semanais, sendo as observações de campo realizadas predominantemente no período vespertino, com dois grupos.

Um dos grupos observados foi o Maternal 1, composto inicialmente por 21 crianças (nascidas entre janeiro e setembro de 2011) tendo sido matriculada mais uma criança no segundo semestre. Esse grupo contava com três educadoras² e ocupava uma sala ampla, com banheiro e solário anexos.

O segundo grupo observado foi a turma de Maternal 2 composto por 29 crianças, tendo a

\footnotetext{
I Sob orientação da Profa Dra. Angela Maria Scalabrin Coutinho.

$2 \quad$ Nesse período a rede municipal de Curitiba tinha em seu quadro de profissionais duas categorias para o trabalho docente na Educação Infantil: professora, que atuava exclusivamente nos grupos Maternal 3 e Pré, e educadora, que atuava em todos os grupos de educação infantil, sendo que nas turmas de Berçário I a Maternal 2 o quadro era exclusivamente composto por educadoras.
} 
equipe de apoio $^{3}$ em sala nos dias de observação. Esta turma fazia uso de uma sala considerada pequena em relação ao número de crianças que a compõe, sem banheiro e sem solário anexo, fazendo uso frequente do espaço físico externo da instituição.

Quanto ao espaço externo do CMEI, de modo geral é um espaço amplo e é composto por dois parques abertos, dos quais um é com areia e o outro com grama, conta também com uma casinha de boneca, um trem e um ônibus de madeira, alguns cavalos confeccionados com pedaços de troncos de árvores fixados ao chão e mesinhas com banco de concreto.

Foto I - Parque externo - ônibus de madeira

Fonte: as autoras

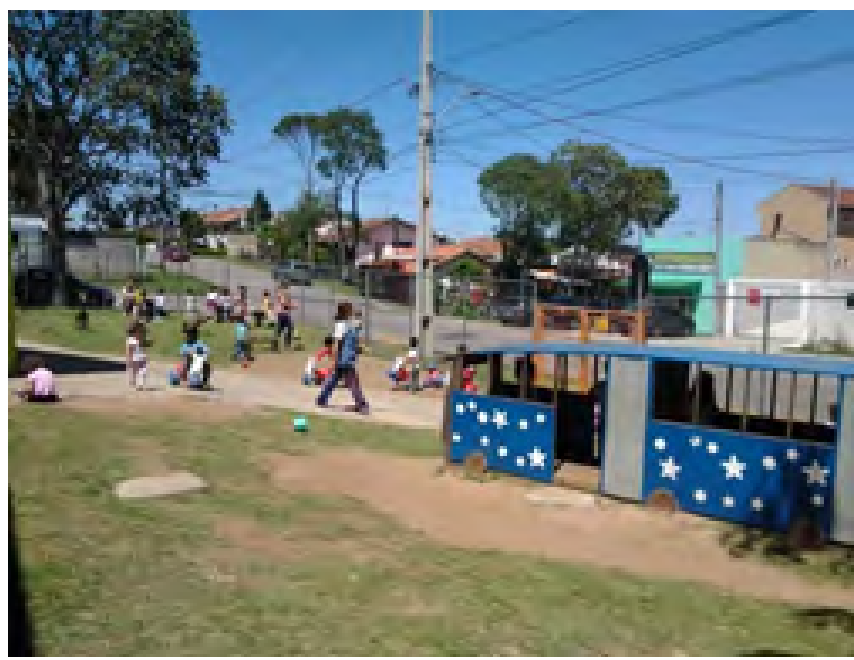

Foto 2 - Parque externo com areia

Fonte: as autoras

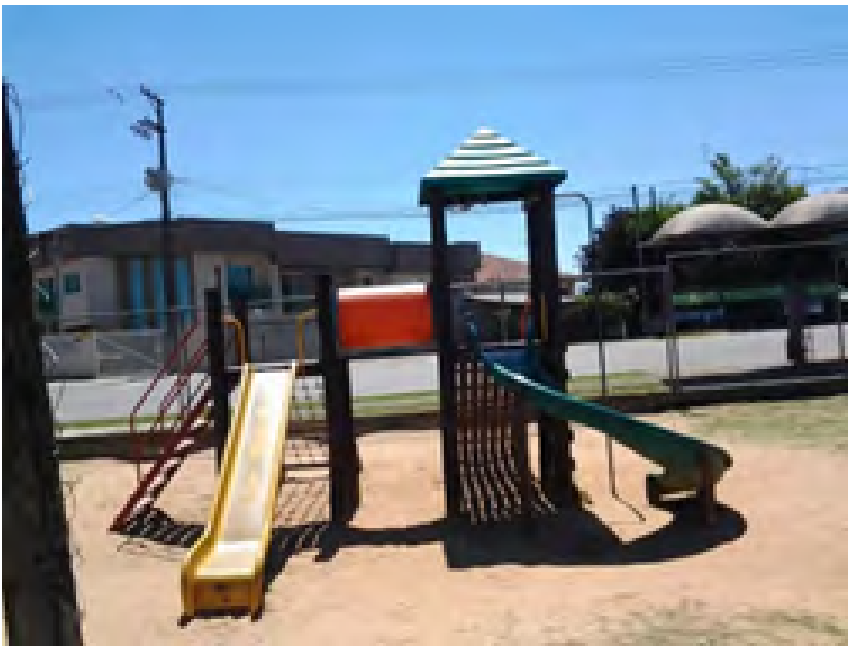

3 Essa equipe de apoio é identificada como equipe de permanência, que se ocupava dos grupos de crianças nos dias da hora atividade ou hora permanência - momento de avaliação e planejamento do cotidiano junto à pedagoga do CMEI - das profissionais que atuavam com os grupos. 
Foto 3 - Mesas de concreto e brinquedos confeccionados com pedaços de tronco de árvores Fonte: as autoras

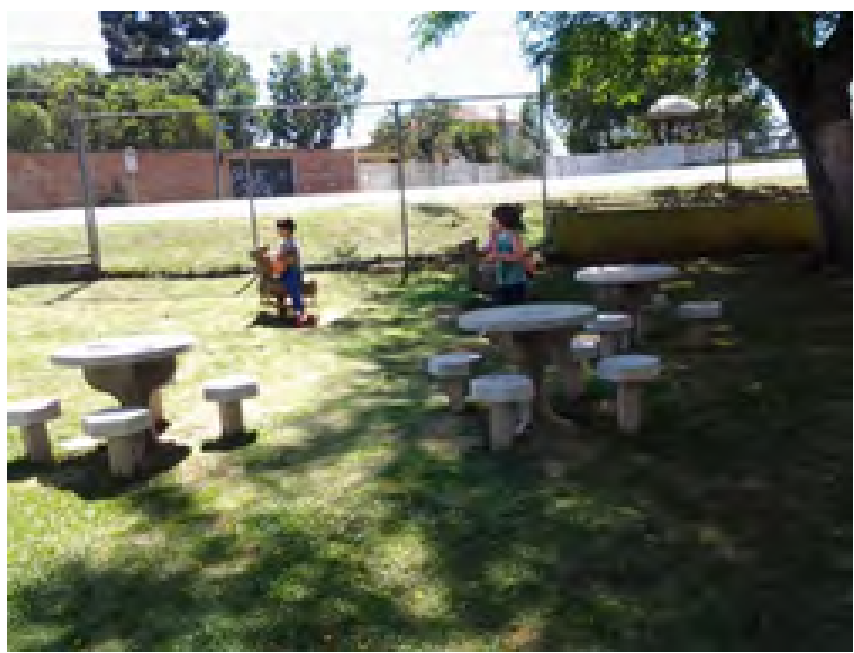

Foto 4 - Vista parcial da área externa Fonte: as autoras

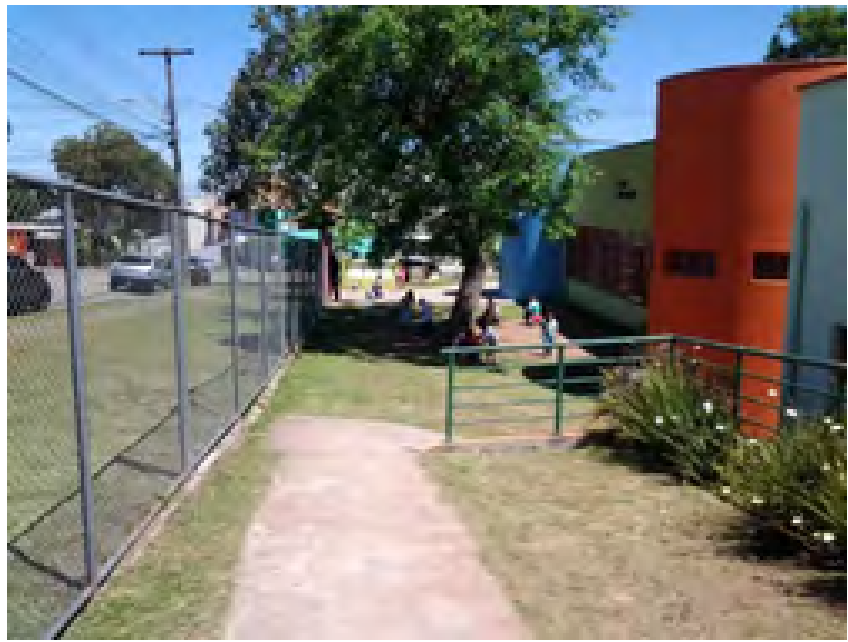

Para o Maternal 1 o solário se configura como uma conexão entre o espaço externo e o interno, esse lugar tem dois toldos móveis para a proteção do sol, contando ainda com a sombra de uma árvore frondosa. Há uma cerca baixa e vazada que o separa do parque, há brinquedos de plásticos, como gangorras e brinquedos para escalar, dispostos pelo espaço. 


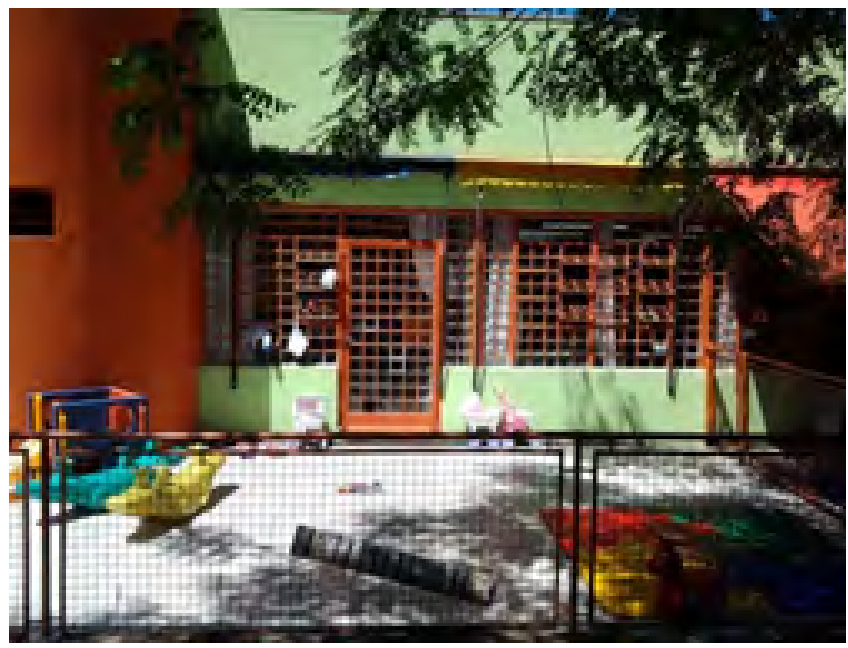

Como é possível observar, a instituição conta com espaços diversificados, que permitem o contato com diferentes materialidades, tais como madeira, ferro, plástico, concreto; com elementos da natureza como árvores, terra, grama e permite o contato com o sol e a sombra. Ainda que o espaço externo possa ser considerado privilegiado pelas inúmeras possibilidades que oferece, abordaremos como os planejamentos os contemplam, no sentido de assegurar que as crianças vivenciem experiências com a natureza e relações sociais nesse contexto.

\section{Os espaços como extensões dos sujeitos}

A educação infantil, como já citamos, é a primeira etapa da educação básica, atende crianças de zero até cinco anos e está fundamentada na LDB 9394/96, que define como finalidade da Educação Infantil o desenvolvimento integral das crianças em seus aspectos físico, psicológico, intelectual e social, complementando a ação da família e da comunidade (Art. 29).

As Diretrizes Curriculares Nacionais para a Educação Infantil (2009a) orientam e balizam as propostas pedagógicas e curriculares considerando a criança como centro do planejamento, visando garantir o acesso a processos de apropriação, renovação e articulação de conhecimentos e aprendizagens de diferentes linguagens, assim como direito a proteção, a saúde, a liberdade, a confiança, ao respeito, a dignidade, a brincadeira, a convivência e a interação com outras crianças (Art. 8).

Entre os aspectos definidos pelas DCNEIs (BRASIL, 2009a) para a efetivação destes direi- 
tos destacamos os incisos V, VI e VII do primeiro parágrafo do artigo $8^{\circ}$, os quais orientam para a promoção da interação entre crianças de diferentes faixas etárias, para os deslocamentos e movimentos nos espaços internos e externos e para a acessibilidade de espaços e materiais, garantindo o acesso de crianças com necessidades especiais; e os incisos VIII e X do artigo nono, os quais preveem o conhecimento das crianças em relação à natureza e a promoção da interação, cuidado, preservação e conhecimento da biodiversidade e da sustentabilidade da vida na Terra.

Ao remeter para os documentos mandatários supracitados identificamos um grande avanço nas orientações para a educação das crianças pequenas, porém nem sempre estes avanços são traduzidos em ações concretas e os direitos proclamados não são totalmente efetivados. Nem todos os aspectos fundamentais para o desenvolvimento das crianças (motor, sensório, simbólico, lúdico, social) previstos em lei são assegurados no cotidiano das instituições de educação infantil.

Pensando no CMEI como um lugar onde as crianças passam grande parte do tempo de sua infância e do seu cotidiano, a instituição de educação infantil tem papel fundamental na garantia destes direitos. Mais especificamente, considerando que a criança se relaciona com o espaço em que está inserida, influenciando-o e sendo influenciada por este, acreditamos que os espaços externos dos CMEIs são fatores determinantes nas relações que são estabelecidas no dia a dia:

Já no parque as crianças ficam livres para brincar, as educadoras levam até o espaço com areia panelinhas, colheres e baldes. Em um primeiro momento as crianças se movimentam muito, correm por todos os lados e depois de algum tempo formam-se grupos em determinados espaços, na casinha, no ônibus, nas mesinhas, na areia e nos pneus. (Registro escrito, 04.07.2013).

Esse excerto de um registro dá visibilidade ao que acontece no horário que é destinado ao espaço externo no campo de estágio observado. Esse momento de interação, aos poucos se torna um intenso momento de trocas, onde ocorrem jogos, brincadeiras, o faz de conta, a formação de grupos ou mesmo experiências individuais. O espaço externo torna-se um espaço de liberdade de escolhas, poder escolher com quem brincar, do que brincar e como brincar.

Percebemos aqui a importância de propor às crianças elementos variados que favoreçam a interação no espaço, pois apesar de sabermos o quão criativas são as crianças, também reconhecemos que elas criam a partir das bases a elas disponibilizadas, sabemos também da importância de valorizar e oportunizar diferentes materiais de exploração, criação e faz-de-conta, pois quanto mais rica as condições das crianças, maior será sua oportunidade de enriquecer também o repertório de suas brincadeiras. 
Acreditamos que diferentes ambientes podem favorecer as mais diversas interações com o meio e com outros sujeitos, tendo a professora o papel fundamental em observar, planejar e organizar os espaços onde ocorrem essas relações. Para isso é necessário que a professora4 esteja atenta às crianças, observando seus diálogos, seus interesses, suas curiosidades, enriquecendo-os a partir das oportunidades que lhes oferece.

Para Carolina Gobbato (2013, p. 13), “A organização do espaço pressupõe intervenções sutis e potentes, as quais, por sua vez compõem a intencionalidade pedagógica que distingue espaços coletivos de educação infantil dos espaços familiares." Portanto, cabe à professora propor elementos que favoreçam a interação nos espaços, permitindo que a criança se aproprie do espaço; é importante planejar a inclusão de brinquedos para diferentes faixas etárias, que provoquem diferentes usos e atividades, inclusive nas áreas externas, permitindo às crianças fantasiar a partir de brinquedos que possam ser explorados e experimentados.

O espaço e a sua organização foi o primeiro assunto abordado em ambos os registros da primeira observação realizada no campo, porém problematizou-se o espaço interno das salas:

Será mesmo este espaço organizado a partir da reflexão de como se pensa a criança e a sua educação? $\bigcirc$ espaço é fruto da relação estabelecida com as crianças? As crianças são convidadas a participar da organização do espaço, incentivando a sensibilidade estética das mesmas? A organização material e de mobiliário é provocadora de interações? O espaço está organizado de modo a contemplar as diferentes dimensões humanas: o lúdico, artístico, afetivo, cognitivo? Há livros, brinquedos e materiais de arte disponíveis às crianças ou ficam na mão apenas do adulto? (Registro escrito, 09.05.2013).

Ao escolher o espaço externo como objeto de estudo, nossa primeira preocupação foi pensar se estas questões também não deveriam ser levantadas quanto à área externa do CMEI. A o pensar em espaço externo é necessário pensarmos nas experiências que ele propiciará às crianças, experiências que envolvam diferentes linguagens por meio de brincadeiras, da interação, da relação que elas estabelecerão com o espaço disposto. Por exemplo, relacionamos muitas vezes as atividades como pintura, desenho, escrita, as brincadeiras com bonecas e carrinhos ao espaço interno, principalmente à sala de referência; ao espaço externo ficam restritas as bolas, os potes para brincar na areia e brincadeiras que na maioria das vezes são um "corre-corre".

Se pensamos no arranjo espacial da sala de referência, na disposição dos móveis, se devemos considerar odores, mobiliários, sons etc. porque também não levamos estas questões para o espaço externo do CMEI?

$4 \quad$ Tendo em vista que todas as profissionais e estagiárias são mulheres, neste texto utilizaremos o termo professora no feminino. 
A área externa muitas vezes não é vista como um espaço de possibilidades, de interação e aprendizagem. Podemos citar inúmeras experiências que poderiam acontecer no espaço externo e sair das quatro paredes da sala e nem por isso deixariam de contribuir com as propostas sugeridas pelos documentos que orientam a prática pedagógica na rede municipal, ao contrário, poderiam enriquecer ainda mais o repertório das crianças. Uma roda de conversa no parque, por exemplo, poderia ser muito interessante para as crianças, as atividades de movimento que são realizadas com músicas poderiam acontecer na grama ou na areia, proporcionando à criança o contato com diferentes texturas, o desenho poderia acontecer nas mesas que estão dispostas na grama e que comportariam muito bem todas as crianças, ou até mesmo em outras bases como o próprio chão ou outras estruturas como os grandes brinquedos, como sugere Anne Marie Holm (2007), enfim são inúmeras as sugestões.

É neste sentido que Zenilda Ferreira (2005) chama a atenção à necessidade de se refletir sobre a dicotomia instaurada entre espaços internos e espaços externos: "o escopo dessa reflexão não é de ordem arquitetônica, como pode parecer, ele está imbricado numa dicotomia que perfaz a história da humanidade, em que corpo e mente ocupam posições distintas”.

Dessa forma ao pensar o espaço educativo não se pode ficar restrito a sala de referência, espaço interno, edificado, mas pensar que todos os espaços da instituição são extensões uns dos outros, e merecem um olhar mais atento com as relações que ali se estabelecem e que podem se estabelecer.

Para Zenilda Ferreira (2005, p.182-183):

É na trama das ações desenvolvidas pelas crianças na sala com as do parque que conheceremos, de fato, nossas crianças. Para isso, é importante ter conhecimento, dos sentidos e significados, atribuídos palas crianças aos materiais, objetos/brinquedos e jogos, como também compreender que as duas modalidades de atividades, livres e orientadas, se constituem como diversas e complementares [...].

No período de observação do Maternal 2, uma única vez as crianças fizeram pintura em papel kraft no espaço externo, mesmo assim com um curto tempo, seguindo o tempo das educadoras, como afirma Zenilda Ferreira (2005, p. 138), “o tempo das crianças é diferente do tempo do adulto. Mesmo no tempo/espaço do parque, considerado como tempo/espaço das crianças, os adultos atropelam o tempo delas.” Já o Maternal 1 possui o espaço externo restrito ao solário, que permite o contato com a natureza, mas muito mais na dimensão da contemplação do que do contato direto, como mostra o excerto do registro realizado no espaço do solário: 
Percebo que Rafaela, Diego e Davi5 estão abaixados próximos ao cercado, observando algo na grade, quando de repente todos eles se levantam e exclamam: "Voou!" e ficam olhando para cima, observando a árvore que fica em frente ao solário do MI, me aproximo e pergunto quem voou, eles então falam juntos e apontam para cima, porém não consigo entender o que falam, as únicas palavras que consegui entender foram "voou" e "joaninha", interpretando a situação acredito que estavam observando algum inseto que voou e os três ficaram admirados ao vê-lo voar, e "sumir" no ar. (Registro escrito, 04.07.2013).

O registro nos permite analisar a importância do olhar atento da professora enquanto observadora, pois como nessa situação, muitos momentos de brincadeiras, de interação, de observação, de curiosidade demonstram a fascinação das crianças por detalhes muito simples aos olhos adultos, mas que são complexos e instigantes para as crianças. É através destes momentos que se cria a possibilidade de conhecer o novo, propondo às crianças situações desafiadoras, provocativas, levando -as a investigar o "objeto de interesse" a fim de que compreendam e aprendam sobre o mesmo na relação com seus pares e com os adultos, desta forma devemos permitir que sua curiosidade excite novas ações.

Segundo os Parâmetros Nacionais de Qualidade para a Educação Infantil (BRASIL, MEC, 2006) as crianças precisam ser apoiadas em suas iniciativas espontâneas e incentivadas a ampliar permanentemente seus conhecimentos a respeito do mundo, da natureza e da cultura. É neste sentido que Barbosa e Horn (2007) vão considerar a importância da professora observar as crianças, seus gostos, suas preferências, suas curiosidades para a partir daí estruturar o espaço e organizar o trabalho. A escuta é, portanto, o verbo mais importante para se pensar e direcionar a prática educativa com crianças (OSTETTO, 2011).

Nessa mesma direção Gobbato (2013, p. 14) ao falar sobre os bebês, sobretudo, os que ainda não falam ou caminham, afirma que:

[...] é preciso estar atento para perceber as suas ações e iniciativas. Caso contrário, corre-se o risco de não se valorizar alguns acontecimentos manifestados por formas discretas e minuciosas de os bebês marcarem presença nesse espaço, como brincar com os raios do sol, sentir a brisa que sopra no ar, explorar a textura de uma folha, observar o caminho das formigas ou um teto que está sempre mudando, percorrer os desníveis encontrados no chão, equilibrar-se sobre eles, entrar em contato com a materialidade que constitui esse chão (areia, grama, pedras, piso), sentir outras temperaturas, cheiros, barulhos diferentes daqueles encontrados entre as paredes da sala.

Precisamos estar atentos às manifestações das crianças, respeitando-as e compreendendo-as como seres capazes de fazer escolhas, explorar, procurar, investigar. Nesse sentido, o espaço externo pode se constituir como um lugar rico em possibilidades e descobertas, promotor de aventuras, desafios, aprendizagem, propiciar as mais diversas interações, entre elas a interação com os elementos 
da natureza, que provoca a curiosidade e desenvolve a criatividade, além de permitir que a criança realize leitura de mundo a partir do conhecimento do meio ambiente, bem como o reconhecimento de seu corpo através das possibilidades de movimentações nas áreas livres.

Ao falarmos da oportunidade de exploração do espaço externo pelas crianças não nos limitamos à oportunidade de promover o desenvolvimento de determinada "competência" cognitiva, social ou motora, mas destacamos a oportunidade da exploração e descoberta dos elementos naturais que ali se encontram, permitindo que as crianças experimentem as mais diversas variações existentes da natureza. Coadunam com esse indicativo as orientações das DCNEIs que definem que "as crianças precisam brincar em pátios, quintais, praças, bosques, jardins, praias, e viver experiências de semear, plantar e colher os frutos da terra, permitindo a construção de uma relação de identidade, reverência e respeito para com a natureza" (BRASIL, 2009, p. 15).

Nos espaços externos as crianças são instigadas a observar e experimentar a diversidade de texturas, sons, cores e sabores, realizando descobertas e encontrando desafios, encantando-se e maravilhando-se com a natureza.

As Diretrizes Curriculares para a Educação Municipal de Curitiba (CURITIBA, 2006, p. 61) apontam para "a necessidade de se romper com a ideia de que há uma ordem de assuntos a serem desenvolvidos com as crianças", orientando para um trabalho com a natureza que se proponha a transformar as curiosidades das crianças e os seus questionamentos em conhecimentos.

Muitas vezes as profissionais se sentem inseguras ao propor a saída para o espaço externo, principalmente com as crianças bem pequenas, por compreenderem o parque como um espaço que oferece certo risco, perigoso às crianças, desta forma anulando a figura da criança competente na vida e na aprendizagem, ativa, crítica e produtora de cultura; o modo que compreendemos as crianças torna-se um fator determinante na definição dos contextos educacionais oferecidos a elas (RINALDI, 2013). Portanto, os riscos não devem inviabilizar o contato dos pequenos com os elementos da natureza, ao contrário, a professora deve pensar e organizar também o espaço externo, transformando-o num espaço acolhedor e seguro, articulando-o com as diversas possibilidades de interações. É neste sentido que Gobbato (2013, p. 15) afirma: "Precisamos inverter a lógica vigente: em vez de os bebês precisarem transformar-se (aprender a caminhar, falar, crescer) para poder frequentar espaços, são os espaços que devem ser transformados para que eles possam utilizá-los!”. 
Segundo a teoria histórico-cultural as funções psicológicas superiores de um sujeito se constroem ao longo de sua história, com isso os processos de mediação, realizados não apenas por professoras, mas por familiares, por outras crianças, enfim, pelos vários interferentes do contexto em que estão inseridas, sofrem transformações ao logo de seu desenvolvimento. Por isso torna-se tão importante para a criança a manipulação, a exploração, o contato com natureza e com outros sujeitos, para a sua constituição como ser humano.

Esta constituição acontece de acordo com Vygotsky (1998) quando as funções no desenvolvimento da criança aparecem primeiro no nível social e depois no nível individual. A bagagem cultural da criança se forma mediante as experiências com o mundo, através da organização da sua realidade.

Para Rinaldi (2013, p. 125) “os caminhos e processos de aprendizagem das crianças passam pela relação com o contexto cultural e escolar que, como tal, deve ser um 'ambiente de formação', um lugar ideal para o desenvolvimento que valoriza esses processos", é neste viés que a professora assume papel crucial na promoção de condições que viabilizem à criança a exploração, experimentação e a (re)construção de significados, enriquecendo cada vez mais seu repertório de vivências.

Deste modo, é preciso instigar na criança atitudes de curiosidade como observar e explorar o ambiente, percebendo-se cada vez mais como integrante, independente e agente transformador do meio ambiente; criar recursos que possibilitem à criança desenvolver conceitos sobre o mundo que a rodeia, manipular, interagir e sentir os diferentes elementos naturais, deixar-se envolver com a textura e temperatura de diversas sensações, ampliando o conhecimento prévio. (GONÇALVES; LEMES; ARAGÃO, 20।4, p.233)

Ao considerarmos o espaço externo como um fator determinante nas relações que se estabelecem no cotidiano dos CMEIs, não podemos desconsiderar o parque como um espaço de brincar. No parque os elementos naturais geram brincadeiras, é ali que pedras, areia, sementes e folhas transformam-se em inúmeras possibilidades de brincadeira, "estar no parque é construir um lugar repleto de descobertas" (VICTÓRIA; BASSETI, 2014, p. 177).

O parque, com frequência, se configura num espaço convidativo, propício para as mais diversas interações e está relacionado a condição de livre arbítrio, as crianças escolhem suas brincadeiras, seus parceiros e os objetos que darão suporte para a brincadeira, constroem seus enredos, criam, recriam, assimilam, experimentam, exploram, inventam, inovam, enfim aprendem com e sobre o meio que as cerca.

Embora a brincadeira seja uma atividade central da infância e aconteça em outros espaços- 
tempos da instituição de Educação Infantil, Victória e Basseti (2014, p. 171) chamam atenção a “maneira como as crianças qualificam suas experiências nos espaços, atribuindo diferentes significados a uma mesma brincadeira em diferentes lugares." É neste viés que Agostinho (2004, p. 8) em sua pesquisa intitulada O Espaço da Creche: Que lugar é este? constata que:

[...] as crianças em suas relações com e no espaço recorreram ao faz-de-conta, a imaginação, imprimindo suas marcas no espaço e, ao fazê-lo, demonstram que têm outro jeito, outros jeitos de se relacionar com o espaço, para além do convencionalmente instituído: vão inventando, inovando, explorando-o de outras formas, dando novos significados aos arranjos e objetos, encontrando novos jeitos de se relacionar com seus objetos e pessoas, sua organização [...].

Salientando:

[...] a importância de planejar e organizar o espaço da creche de forma que os meninos e meninas que ali passam o dia todo em todos os dias durante a semana, tenham o seu direito à brincadeira garantido, com muitos e diversos brinquedos e que estes estejam acessíveis, inteiros, limpos, disponibilizados de forma criativa e convidativa. É preciso observar a variedade desses brinquedos no que diz respeito ao material, cor, textura, tamanho, para que possamos pluralizar, enriquecer as interações com culturas diversas, cuidando para não valorizarmos brinquedos estereotipados que reafirmam a lógica e os discursos de um sistema consumista, preconceituoso e excludente. Entendo ser possível e viável aproveitar ao máximo materiais de reciclagem e elementos da natureza, buscando saídas criativas e humanizadoras. (AGOSTI$\mathrm{NHO}, 2004$, p. 8-9 grifos nossos)

É nesse sentido que ao abordarmos este tema buscamos voltar um olhar mais crítico para o espaço externo e seu aproveitamento, propondo que novas opções sejam consideradas, para que este espaço seja valorizado e faça parte do cotidiano das crianças e das educadoras nos planejamentos de suas práticas.

\section{Espaço como elemento educativo: algumas considerações}

Com as observações de campo e o estudo da importância dos espaços de Educação Infantil, relacionando com a perspectiva histórico-cultural, percebemos a necessidade de se repensar o espaço externo e suas proposições, pois assim como o espaço interno, pensar, projetar, disponibilizar e organizar o espaço externo para as crianças exige que as conheçamos e as incluamos nesse processo.

Entender os espaços como extensões dos sujeitos, ou seja, como um lugar, é crucial para que se possa otimizar o seu uso, ampliando as oportunidades de experiências das crianças, compreendendo o espaço, não como construção, edificação, espaço físico apenas, mas sim como elemento educativo, lugar onde as crianças têm oportunidade de se movimentar amplamente, fazer escolhas, determinar seus próprios tempos, de se envolver em relações e interações sociais e naturais, como afirma Vinão-Frago (2001, p. 61) “o espaço se projeta ou se imagina; o lugar se constrói... a partir 
do fluir da vida e a partir do espaço como suporte; o espaço, portanto, está sempre disponível e disposto a converter-se em lugar, para ser construído".

O espaço externo por si só é rico em oportunidades, mas para que se torne um espaço educativo, um lugar, e de possibilidades é necessário que seus elementos sejam adequados às propostas pedagógicas, que as professoras não tenham medo de novas experiências, de novas rotinas, de novas propostas, é necessário conhecer o espaço, planejar, imaginar, repensar e proporcionar às crianças usos diversificados e enriquecedores:

A professora e o professor necessitam articular condições de organização dos espaços, tempos, materiais e das interações nas atividades para que as crianças possam expressar sua imaginação nos gestos, no corpo, na oralidade e/ou na língua de sinais, no faz de conta, no desenho e em suas primeiras tentativas de escrita. A criança deve ter possibilidade de fazer deslocamentos e movimentos amplos nos espaços internos e externos às salas de referência das classes e à instituição, envolver-se em explorações e brincadeiras com objetos e materiais diversificados que contemplem as particularidades das diferentes idades, as condições específicas das crianças com deficiência, transtornos globais do desenvolvimento e altas habilidades/superdotação, e as diversidades sociais, culturais, étnico-raciais e linguísticas das crianças, famílias e comunidade regional. (BRASIL, 2009, p. 14).

É neste sentido que o espaço externo pode propiciar diversas experiências de conhecimento de mundo e das relações, considerando que nele as crianças vão em busca de descobertas, desafios; levantam questionamentos e vão em busca das respostas.

Por fim, salientamos que embora não tenha sido foco deste trabalho, não podemos deixar de mencionar que a categoria espaço está diretamente relacionada à categoria tempo, ou seja, ao problematizar o espaço externo para as crianças devemos considerar que o tempo para as experiências nesse contexto deve ser constantemente pensado e planejado, o que significa compreender a instituição de educação infantil como lugar de vida.

\section{Referências}

AGOSTINHO, K. A. O espaço da creche: que lugar é este? Dissertação de Mestrado em Educação, Universidade Federal de Santa Catarina, Florianópolis, 2003.

AGOSTINHO, K.A. O espaço da creche: que lugar é este? In: 27a Reunião Anual ANPED, Caxambu, 2004. Disponível em; <http://27reuniao.anped.org.br/gt07/t073.pdf> Último acesso em 07.12.2014.

BARBOSA, M. C. S.; HORN, M. da G. S. Organização do espaço e do tempo na escola infantil. Em: CRAIDY, C. M.; KAERCHER, G. E. (orgs.). Educação Infantil: pra que te quero? Porto Alegre: Artmed, 2001, p. 67-79.

BRASIL. Lei no 9.394/96. Casa Civil. Lei de Diretrizes e Bases da Educação Nacional. Brasília, 1996. 
BRASIL. Ministério da Educação. Secretaria de Educação Básica. Parâmetros Básicos de Infra-estrutura para Instituiçóes de Educação Infantil. Brasília: MEC, SEB, 2006.

BRASIL. Ministério da Educação. Conselho Nacional de Educação. Câmara de Educação Básica. Parecer CNE/CEB n. 20, de 11 de novembro de 2009. Revisão das Diretrizes Curriculares Nacionais para a Educação Infantil. Diário Oficial [da] República Federativa do Brasil, Brasília, DF, Seção 1, 9 dez. 2009.

BRASIL. Resolução no 5/09. Conselho Nacional de Educação. Diretrizes Curriculares Nacionais para a Educação Infantil. Brasília, 2009a.

CARVALHO, M. I. C. de; RUBIANO, M. R. B. Organização do Espaço em Instituições Pré-escolares. Em: OLIVEIRA, Z. M. R. de (org.) Educação Infantil: muitos olhares. São Paulo, Cortez, 1994, p. 107-131.

CURITIBA. Prefeitura Municipal de Curitiba. Diretrizes Curriculares para a Educação Municipal de Curitiba. Vol 2. Educação infantil. Curitiba: SME, 2006.

CURITIBA. Prefeitura Municipal de Curitiba. Organização de Espaços Externos das Instituiçóes de Educação Infantil: Orientaçôes Básicas para CMEIs, CEIs Conveniados e Escolas com Educação Infantil. Educação Infantil. Curitiba: SME, 2013.

FERREIRA, Z. Tempos e Espaços para Brincar: o Parque como Palco e Cenário das Culturas Lúdicas. In: ROCHA, E.A.C.; KRAMER, S. (orgs.). Educação Infantil: Enfoques em Diálogos. Campinas: Papirus, 2013, p. 157-176.

FRANCISCO, Z.F.; "Zê,tá pertinho de ir pro parque?”: o tempo e o espaço do parque em uma instituição de educação infantil. 2005. 197f. Dissertaçáo (Mestrado em Educação) - Universidade Federal de Santa Catarina, Florianópolis, 2005.

GOBBATO, C. Para além da sala do berçário em Revista Pátio - Educação Infantil. Ano XI, n³5 abrljun 2013 p. $12-15$

GONÇALVES, S.R.; LEMES, S.A.; ARAGÃO, V.C. Bebês e a interação com o meio naturalIn: PEIXE, D.C.S.; NEIVERTH, T. (orgs.) Creches Catarinenses: experiências de formação e práticas pedagógicas. Florianópolis: UFSC-CED-NUP. 2014, p. 227-242.

HOLM, A. M. Baby-art. Os primeiros passos com a arte. São Paulo: Museu de Arte Moderna de São Paulo, 2007.

MARTINS, R.C. A organização do espaço na Educação Infantil: o que contam as crianças? 2010. 166f. Dissertação (Mestrado em Educação) - Universidade Federal do Paraná, Curitiba, 2010.

OSTETTO, L. E. Planejamento na Educação Infantil: mais que a atividade, a criança em foco. Em: OSTETTO, L. E. (org.). Encontros e encantamentos na educação infantil. Campinas: Papirus, 2000, p.175-200.

RINALDI, C. O Ambiente da Infância In: CEPPI, G.; ZINI, M. (orgs.) Crianças, espaços, relaçóes: como projetar ambientes para a educaçáo infantil. Porto Alegre: Penso, 2013, p. 122- 128.

VICTÓRIA, A.C.M.; BASSETI, Y.R. O espaço-tempo observado, vivido e repensado com as crianças In: PEIXE, D.C.S.; NEIVERTH, T. (orgs.) Creches Catarinenses: experiências de formação e práticas pedagógicas. Florianópolis: UFSC-CED-NUP, 2014, p. 165 - 183.

VIÑAO-FRAGO, Antonio. Do espaço escolar e da escola como lugar: propostas e questóes. In: 
Currículo, espaço e subjetividade: a arquitetura como programa. Frago, AntonioViñao e Escolano, Augustín. Trad. Alfredo Veiga-Neto. 2.ed.. Rio de Janeiro: DP\&A, 2001, p. 62- 39.

VYGOTSKY, L. S. Pensamento e Linguagem. São Paulo: Martins Fontes, 1998. 